\section{CORRESPONDENCE}

\section{But what of designer drugs?}

Abraham \& Luty (2010) provide a useful overview of testing for illicit drugs in clinical practice. I had hoped that the article would also tackle the more thorny issue of designer drugs. Our team is increasingly involved in cases of designer drug misuse that results in complex management problems.

At present there is no way of testing for designer drugs on the ward, so tests have to be sent to one of a handful of national testing centres. Conventional drug testing involves immunoassay of urine, but to accurately identify designer drugs requires the use of mass spectrometry. This means that it takes an average of 2 months for results to become available. We find it very difficult to make use of such old data as all too often they are no longer relevant.

This problem is not likely to be resolved in the near future, owing to the nature of the everevolving designer drugs industry. In view of this, we need to rethink our traditional approach to drug testing and monitoring.

Abraham A, Luty J (2010) Testing for illicit drug use in mental health services. Advances in Psychiatric Treatment 16: 369-79.
Michael C. F. Smith, Forensic Psychiatrist, Yorkshire. Email: mcfsmith321@yahoo.co.uk

doi: 10.1192/apt.17.2.158

\section{Numbers-needed-to-treat analysis}

In their excellent article, Hodgson et al state, 'By convention, the NNT and NNH are always rounded up to the nearest whole figure' (Hodgson 2011). A more cautious convention is to round the number needed to treat (NNT) up, to avoid overstating the effectiveness, and to round the number needed to harm (NNH) down, to avoid understating the harms (BMJ 2011).

BMJ (2011) Helping you to practise evidence-based medicine. Clinical Evidence glossary. BMJ Publishing Group (http://clinicalevidence.bmj. com/ceweb/resources/glossary.jsp).

Hodgson R, Cookson J, Taylor M (2011) Numbers-needed-to-treat analysis: an explanation using antipsychotic trials in schizophrenia. Advances in Psychiatric Treatment 17: 63-71.

Daniel McQueen, Barnet Enfield and Haringey Mental Health Trust, London, UK. Email: daniel.mcqueen@virgin.net doi: 10.1192/apt.17.2.158a

\title{
CORREction Correction
}

Hodgson R, Cookson J, Taylor M (2011) Numbers-needed-to-treat analysis: an explanation using antipsychotic trials in schizophrenia Advances in Psychiatric Treatment 17: 63-71.

In Table 5 of the above, the entry in the last cell of the Olanzapine row should read 13. The corrected table appears below.

Numbers needed to treat (NNT) for all-cause discontinuation for the Tiihonen study

\begin{tabular}{|c|c|c|c|c|c|c|c|}
\hline & & & & Comparator & & & \\
\hline & & Clozapine & Olanzapine & Perphenazine & Risperidone & Haloperidol & $\begin{array}{c}\text { Depot } \\
\text { perphenazine }\end{array}$ \\
\hline & Clozapine & & 6 & 2 & 4 & 2 & 15 \\
\hline Primary & Olanzapine & -6 & & 2 & 8 & 2 & 13 \\
\hline & Perphenazine & -2 & -2 & & -4 & 5 & -2 \\
\hline & Risperidone & -4 & -8 & 4 & & 2 & -4 \\
\hline & Haloperidol & -2 & -2 & -5 & -2 & & -2 \\
\hline & Perphenazine depot & -15 & -13 & 2 & 4 & 2 & \\
\hline
\end{tabular}

a. The figures for NNT represent the advantage of the drug in the left-hand column over the drug in the top line. A negative NNT means the drug on the left is less effective. Data source: Tiihonen 2006 